\title{
Brain infiltration by cancer cells: different roads to the same target?
}

\author{
Mayra Paolillo, Sergio Schinelli \\ Department of Drug Sciences, University of Pavia, 27100 Pavia, Italy.
}

Correspondence to: Dr. Mayra Paolillo, Department of Drug Sciences, University of Pavia, 27100 Pavia, Italy. E-mail: mayra.paolillo@unipv.it

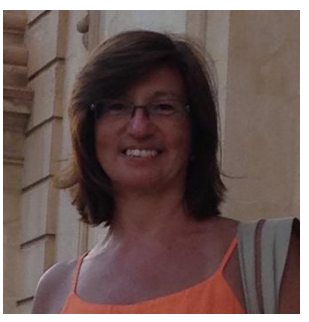
Mayra Paolillo is research associate at the Drug Sciences Department, University of Pavia, Italy. Her researches
mainly deal with the study of functional effects and signal transduction pathways modulated by the pharmacological
blocking of RGD-binding integrins in glioma cancer stem cells and glioma cell lines.

Brain infiltration by cancer cells is a complex process in which metastatic cells detached from the primary tumor must firstly survive in the blood flow, cross the blood brain barrier (BBB) and finally colonize a foreign microenvironment. The cells that successfully bypass the cellular barriers surrounding capillaries, proliferate to form micrometastasis and trigger the angiogenetic process. Different molecular mechanisms have been proposed to explain the metastatic behaviour of solid tumors that infiltrate brain tissue; in this review the most recent findings concerning mechanisms and genes potentially involved in brain metastasis, that differ according to primary tumor types, will be discussed. The three tumors that more frequently develop brain metastasis, lung cancer, breast cancer and melanoma, will be considered and, in addition, the role of BBB and the process of endothelial to mesenchymal transition in cancer metastasis will be briefly described.

Key words: Brain metastasis; breast; epithelial-mesenchymal transition; lung; melanoma; micro-RNA

\section{INTRODUCTION}

The prognosis for cancer patients is strictly dependent on the metastatic behaviour of the tumor. Each tumor displays preferential sites were metastases more frequently develop and patients survival depends upon the possibility to perform surgery followed by oncological therapy and radiotherapy. Indeed, these approaches are usually sufficient to eradicate local oligometastases but unfortunately the picture is different in the case of brain metastases (BM), which are frequently associated with a poor prognosis. ${ }^{[1]}$ In the case of BM, stereotaxic radiosurgery is a useful tool to reduce local recurrence and achieve the same level of local control of whole-brain radiation therapy, with fewer side effects and comparable outcomes. ${ }^{[2]}$

BM affect up to $40 \%$ of metastatic cancer patients ${ }^{[1]}$ and the

\begin{tabular}{|l|l|}
\hline \multicolumn{2}{|c|}{ Access this article online } \\
\hline Quick Response Code: & Website: \\
\hline & www.jcmtjournal.com \\
\cline { 2 - 2 } & \\
\hline
\end{tabular}

tumors that most often spread to the brain are lung cancer (30-50\% of patients) and breast cancer (10-30\% of patients), with melanoma ranking at the $3 \mathrm{rd}$ place (6-10\% of patients). ${ }^{[3]}$ In many cases, the poor life expectancy associated with BM is due to other widespread metastasis but this is not true for melanoma patiens, who very early display BM that make unsuccessful further therapeutic efforts. ${ }^{[4]}$

Without treatment, median survival for a patient with BM is estimated to be about 3 months for a single lesion, although life expectancy has recently increased due to enhanced diagnostic tools that may even detect very tiny neoplastic formations. ${ }^{[4]}$

Cancer cells traveling through the bloodstream eventually colonize a vascular place, by adhering to endothelial cells, or

This is an open access article distributed under the terms of the Creative Commons Attribution-NonCommercial-ShareAlike 3.0 License, which allows others to remix, tweak, and build upon the work non-commercially, as long as the author is credited and the new creations are licensed under the identical terms.

For reprints contact: service@oaepublish.com

How to cite this article: Paolillo M, Schinelli S. Brain infiltration by cancer cells: different roads to the same target? J Cancer Metastasis Treat 2016;2:90-100.

Received: 10-10-2015; Accepted: 30-11-2015. 
cross the brain barrier to begin the process that leads to the niche formation in the brain parenchyma. Thereafter cancer cells grow and invade the brain tissues by different mechanisms, such as expansive growth, multicellular migration and individual cell migration. ${ }^{[5]}$

On the other side, the host tissue re-organizes its structure and vasculature recruiting stromal cells, such as fibroblasts, endothelial cells and tumor-associated macrophages, that sustain the tumor growth by producing and releasing extracellular matrix (ECM) proteins, cytokines and growth factors. ${ }^{[6]}$

\section{METASTASIS FORMATION: EPITHELIAL- MESENCHYMAL TRANSITION}

The epithelial to mesenchimal transition (EMT), identified as one of the earliest steps of solid tumor progression, is associated with tumor growth, invasion, metastasis and contributes to the conversion of tumors from low- to highgrade malignancy. ${ }^{[7]}$ In epithelium-derived carcinoma, the EMT program induces a series of functional and structural changes aimed at the formation of tumor cells that will be able to invade surrounding tissues and lead to metastases formation. Invasion is a key step to progression toward a malignant phenotype and occurs when tumor cells translocate from the relatively constrained initial neoplastic mass into neighbouring host tissues. To accomplish this task, cancer cells must somehow detach from the primary tumor and migrate through the ECM, opening up the opportunity to penetrate the basal membrane surrounding a blood or lymphatic vessel, travel throughout the body via the circulatory system, and colonize distant sites to form metastatic foci. EMT is acknowledged to confer to cancer cells the molcular features required for these tasks. During EMT, in fact, epithelial cells undergo a developmental switch that results in decreased adhesion and loss of cell polarity, increased proliferation, motility and invasiveness; these changes are associated with the downregulation of epithelial cell surface markers and cytoskeleton components (E-cadherin, zonula occludens-1, claudins, occludins, cytokeratins) and the upregulation of mesenchymal markers (vimentin and $\alpha$-smooth muscle actin) together with ECM components (collagens and fibronectin). ${ }^{[8]}$ Although the molecular changes that occur in cancer cells during EMT have been extensively documented, the molecular switches that turn on EMT still represent an open question and a crucial challenge because the possibility to inhibit this process could be of great impotance in reducing metastatic spread. In vitro and in vivo model systems have identified several transduction pathways that lead to EMT and EMTlike phenotypes, many of which connect EMT to the ECM and the microenvironment surrounding tumors. ${ }^{[9]}$

Among these pathways, integrins and transforming growth factor-beta (TGF- $\beta$ ) work synergistically to drive tumor cells towards EMT. ${ }^{[9-11]}$ TGF- $\beta$, in fact, is secreted as inactive precursor in a complex with 2 peptides, latency associated peptide (LAP) and latent TGF- $\beta$-binding protein (LTBP). Its activation requires the dissociation from the complex, that may also be achieved by several integrins. The LAP peptides bound to TGF- $\beta 1$ and TGF- $\beta 3$ contain an Arginine-Glycine-Aspartate (RGD) motif that can be recognized by the RGD-binding integrins $(\alpha v \beta 3, \alpha v \beta 5$, $\alpha 5 \beta 1$ ); this binding activates a driving force that leads to breaking of LAPs and LTBP binding to TGF- $\beta$ and releases the active form of TGF- $\beta .^{[10,12]}$ Integrin inhibitors with different molecular structures have been studied and are in clinical trials as anti-angiogenic agents or in support of other anti-cancer therapies, therefore integrin antagonists could represent a valuable and near-at-hand tool to inhibit the integrin dependent TGF- $\beta$ activation and eventually reduce metastatic spread. ${ }^{[13]}$

Lung, breast cancer and melanoma are tumors that display the EMT phenotype, ${ }^{[14,15]}$ and in lung cancer, the expression of markers of this transition has been associated with prognosis. ${ }^{[16-18]}$ This link between EMT and malignancy is further supported by the finding that, in other cancer types, EMT markers are overexpressed in $40 \%$ of tissue samples and are associated with vascular invasion and advanced clinical stage. ${ }^{[19]}$

Once in the brain tissue, during reimplantation, the circulating tumor cells have been shown to undergo a mesenchimal to epithelial transition, thus reversing the EMT, to reacquire some of the original epithelial features necessary to survive in the new environment. ${ }^{[20]}$

The knowledge of EMT mechanisms could clearly be an invaluable tool in defining molecular markers predicting tumors metastatic behaviour and prognosis and in identifying targets for new molecules that could inhibit the EMT process.

\section{THE ROLE OF MICRO-RNAS}

A number of recent studies has identified micro-RNAs (miRNAs) as key regulators of cancer cells survival and metastatic spread. Indeed, approximately $30 \%$ of human genes are likely to be regulated by miRNAs ${ }^{[21]}$ and miRNAs have been shown to regulate a variety of biological processes, including cell proliferation, cell differentiation and cell death. ${ }^{[22]}$ In this section miRNA involved in metastases, though with different molecular mechanisms are described.

miRNAs are an endogenous, highly conserved class of non-coding 20-24 nucleotides small RNAs that regulate gene expression at post-transcriptional level by binding to 3'-UTR of target mRNAs, thus leading to inhibition of mRNA translation and degradation. ${ }^{[23]}$ Several reports have elucidated the role of certain miRNAs as a class of oncogenes or tumor suppressors, depending upon their targeted genes. ${ }^{[24]}$ In addition, several studies have reported 
that miRNAs genomic locations are frequently associated to genomic regions involved in cancer. It has been calculated that about $50 \%$ of known miRNAs are located inside or close to fragile sites in minimal regions of loss of heterozygocity, regions of amplifications and common breakpoints associated with cancer. ${ }^{[25,26]}$

These studies indicate that miRNAs represent key players in cancer development and moreover, accumulating evidence demonstrates that miRNAs can also influence multiple steps of metastasis such as EMT, tumor cell migration, invasion and colonization. ${ }^{[27]}$

The miR-200 family (miR-200a, miR-200b, miR-200c, miR-141 and miR-429) and miR-205 were the first group of miRNAs found downregulated in various tumors that underwent EMT progression. Members of the miR-200 family inhibit the EMT process by positively regulating E-cadherin expression through direct targeting of ZEB1 and ZEB2, transcriptional repressors of E-cadherin. Furthermore, expression of the miR-200 family in mammary carcinoma cells induced mesenchymal-epithelial transition by up-regulating E-cadherin expression and inhibited migration of these tumor cells, ${ }^{[28]}$ thus suggesting that downregulation of these miRNAs may be an important step in tumour progression.

miR-145 was found downregulated in several tumor types including breast, gastric, lung, ovary, prostate cancer and esophageal squamous cell carcinoma and notably, accumulating evidence indicates that the processing of miR-145 is also involved in cancer metastasis. ${ }^{[22,29]}$ In breast cancer, miR-145 suppress breast cancer cell line invasion and metastasis by targeting mucin-1, a glycoprotein that can help tumor cells to escape immunosurveillance; ${ }^{[30]}$ in addition, miR-145-dependent regulation of 3'UTR of the JAM-A and fascin decreased motility and invasiveness of MDA-MB-231, MCF-7 and other breast cancer cells. ${ }^{[31]}$

miRNA analysis could also be intrumental for prognostic purposes: in a retrospective study on 256 melanoma patients, divided into three cohorts, four miRNAs (miR-150-5p, miR15b-5p, miR-16-5p and miR-374b-3p) were identified as a prognostic signature that, in combination with stage, was able to distinguish primary melanomas that metastasized to the brain from non-brain metastatic primary tumors. ${ }^{[32]}$ Although at the present time the biological significance of these miRNAs disregulation may be difficult to understand, nevertheless the notion, togheter with classical staging parameters, could be of great importance to clinicians to set specific therapeutic strategies.

Interestingly, miRNA can also modulate gene expression in adjacent cells within the microenvironment and even in distant cells, since miRNAs have been detected in the blood and in other body fluids; ${ }^{[33]}$ indeed, circulating miRNAs, extra-cellular vesicles-and exosomes-associated miRNA are extensively studied as potential biomarkers in different cancer types. ${ }^{[34]}$

Exosomes are 40-100 nm vesicles secreted by a wide range of mammalian cell types, including cancer cells. ${ }^{[35]}$ miRNAs shuttled by exosomes involved in cancer metastases have been found to be implicated in angiogenesis and tumor niche formation. ${ }^{[36,37]}$

Recently, an interesting study reported a new and unexpected mechanism by which a miRNA contributes to metastatic spread in the brain; the miR-181c contained in cancer-derived extra-cellular vescicles, carrying proteins and miRNAs, promotes the destruction of blood brain barrier (BBB) through delocalization of actin fibres via the downregulation of 3-phosphoinositide-dependent protein kinase-1 in vitro and in vivo. ${ }^{[38]}$ The breakdown of $\mathrm{BBB}$ triggered by miR-181c can easily open the way to brain parenchyma to circulating cancer cells.

A very recent study has demonstrated that miRNAs contained in exosomes released by human and mouse tumors that metastasize to lung, liver or brain, like breast cancer, trigger cellular changes in target organs by promoting the formation of tumoral niche and organ-specific invasion. The organ sites where tumor derived exosomes take contact and release their content is related to integrins expressed on the exosomes surface: $\alpha 6 \beta 4$ preferentially interacts with lung cells, $\alpha v \beta 5$ mediates exosomes delivery to liver. ${ }^{[39]}$

These new findings suggest that the exosome miRNAs content and integrin expression can be useful to predict the tendency of primary tumors to metastasize and to determine the preferential organ sites of future metastases; in addition, this evidence highlights the role of integrins as potential valuable targets to inhibit exosomes interactions with metastatic sites.

\section{CROSSING THE BBB}

The key step during BM formation is the migration of cancer cells through BBB. Anatomically, the BBB is formed by brain microvascular endothelial cells (BMVECs), that form tight junctions without pores, and perivascular elements including pericytes, astrocytes, oligogendrocytes and the basement membrane. This complex structure represents a physical barrier for cells and molecules, selected on the basis of their molecular weight and charge. In addition, this barrier regulates the diffusion processes and the brain parenchyma homoeostasis by highly selective transport mechanisms mediating flux of solutes and molecules and by a metabolic barrier consisting of highly specific enzymes. ${ }^{[40]}$

Tumor cells recognize and bind to components of the vascular membrane, thereby initiating extra-vasation and promoting the formation of the tumoral niche that will host the new neoplastic formation. The brain vascular 
endothelium is therefore very important in counteracting cell extra-vasation but, nevertheless, cancer cells adopt different strategies to overcome this obstacle. Although the exact molecular mechanisms that trigger BM are still poorly understood, increasing evidence are shedding new light on the processes underlying the ability of cancer cells to cross the $\mathrm{BBB}$.

In a transendothelial migration model, highly metastatic melanoma cells migration has ben found to be mediated by interaction of the $\alpha 4 \beta 1$ integrin with its ligand vascular cell adhesion molecule-1 (VCAM-1) on the surface of activated endothelial cells. VCAM-1 is expressed by endothelial cells only upon activation by inflammatory stimuli like TNF- $\alpha$ or interferon- $\gamma$, suggesting that highly metastatic melanoma cells preferentially leave the blood vessels at sites of inflammation. ${ }^{[41]}$

In a very similar experimental model, the matrix metalloproteinase 1 (MMP1) was found to play a critical role in BBB penetration; in parallel experiments cyclooxygenase- 2 (COX2)-mediated prostaglandin synthesis promotes proliferation of tumor initiating cells by activating tumor-associated astrocytes followed by secretion of the chemokine CCL 7. ${ }^{[42]}$

The process of transendothelial migration of melanoma cells has been further investigated by other in vitro studies showing that the ability of these cells to cross the BBB is related to melanotransferrin expression levels on the cell surface, to the fibrinolytic system and to serine proteases released by melanoma cells. ${ }^{[43-45]}$

This accumulating evidence indicates that inflammatory stimuli cotribute to the formation of breaches in BBB and of a suitable surrounding in the brain parenchyma for cancer cells.

However, in contrast with these findings, other in vivo studies suggest that trasendothelial cancer cells migration does not necessarily imply a damage to vascular endothelial cells: metastatic breast cancer cells, in mice, were found to cross the endothelium in correspondence of sites where the vessel wall shows discontinuity sites without causing apoptosis or hypoxia in endothelial cells. ${ }^{[46]}$

Another interesting in vivo study demonstrated by multiphoton laser scanning microscopy that in the mouse brain the essential steps in melanoma and lung cancer metastasis formation were first the arrest at vascular branch points and after extra-vasation, perivascular growth in close contacts to microvessels. ${ }^{[47]}$

In this scenario, the interactions of metastatic tumor cells with BMVECs appear to be regulated by a number of effectors and mediators and represent a key step of metastasis formation; however, the cellular mechanisms that lead to BBB extra-vasation appear to be strictly related to cancer cells features and therefore linked to the primary tumour characteristics. ${ }^{[48]}$

Two very recent studies have demonstrated that meningeal lymphatic vessels are present in mouse central nervous system (CNS) and display all the classical features of lymphatic vessels. ${ }^{[49,50]}$ These findings have highlighted a new path for cerebrospinal fluid flux and for immune cells leak, opening interesting avenues for future researches on BM formation.

\section{LUNG CANCER}

Lung cancer is the leading cause of cancer-related deaths worldwide and is characterized by rapid progression and metastases to brain that develop within months of diagnosis and simultaneously affect different organs besides the brain. ${ }^{[51]}$ Lung cancer is classfied into two broad histological sub-types: Non-small-cell lung cancer (NSCLC), representing about $85 \%$ of diagnoses, and SCLC, accounting for the remaining $15 \%$; NSCLC is further classified into adenocarcinoma, squamous-cell carcinoma, and large-cell carcinoma. ${ }^{[52]}$ SCLC and NSLC are traditionally considered as different cancer types but increasing evidence supports the notion that the two histological sub-types can coexist. This mixed histology reinforces the hypothesis of common mutated precursors for the two cancer types thus complicating prognosis and therapy. ${ }^{[52]}$

Although several mechanisms concerning lung cancer cells survival strategies have been elucidated, the early molecular processes leading to BM are still poorly understood.

In SCLC patients BM are associated with poor prognosis. Previous evidence indicated that attachment to brain microvasculature represented the first step for tumor cell extra-vasation and growth. ${ }^{[33]}$ In particular, it was demonstrated that the interaction of SCLC cells with human BMVECs triggers the disassembly of tight junctions between brain endothelial cells and contributes to SCLC cells transendothelial migration, ${ }^{[54,55]}$ thus suggesting that brain microvasculature and mechanisms that regulate cell-cell adhesion are likely to play an important role in SCLC metastasis to brain. An intriguing mechanism was highlighted in a study reporting that the interaction of SCLC cells with BMVECs induces tumor cells to secrete annexin A1 into tumor metastastic microenvironment. The secreted annexin A1, previously reported to be upregulated in human lung cancer and to be related to poor prognosis, in turn promoted SCLC cells adhesion to brain endothelium and transendothelial migration. ${ }^{[56,57]}$

Other studies have shown that SCLC cells are abundantly surrounded by ECM components, including collagen IV, tenascin, fibronectin and laminin; high expression of these components is associated with a poor prognosis. ${ }^{[58]}$ 
Adhesion of SCLC cells to the ECM components requires $\beta 1$-integrins, whose activation results in suppression of chemotherapy-induced apoptosis by stimulation of the PI3K-dependent pathway. ${ }^{[59]}$ Thus, ECM via $\beta 1$ integrinmediated PI3K activation confers to SCLC resistance to apoptosis, allowing SCLC cells to survive even in presence of DNA damage.

Taken together, this evidence indicates that adhesion processes play important roles in SCLC cells survival strategies linked to metastasis and furthermore suggest that interference with adhesion molecules or receptors could be an interesting topic for future researches.

Approximately $40 \%$ of all NSCLC patients suffer from BM. The prognosis of patients with BM of NSCLC is remarkably poor, with a median survival time of 1-2 months for untreated patients and 6 months for those receiving surgery, radiotherapy and chemotherapy. ${ }^{[60]}$ While SCLC metastatic brain tumors do not respond to systemic chemotherapy and poorly respond to molecularly targeted therapies, ${ }^{[58]}$ NSCLC patients frequently display activating epidermal growth factor receptor (EGFR) mutations. ${ }^{[61]}$ Complete and partial response rates to tyrosine kinase inhibitors have been recorded in clinical studies with gefitinib and erlotinib ${ }^{[62,63]}$ and these treatments improved overall survival (OS) rates. However, other genes or genetic alterations have been reported to be involved in $\mathrm{BM}$ of lung cancer.

An interesting study performed by microarray in lung adenocarcinoma and squamous cell carcinoma samples has shown different expression profiles of EMT-related genes in primary tumors compared to tumor-derived BM. ${ }^{[64]}$ In particular, BM had signifi cantly lower integrin $\alpha v \beta 6$ and $\mathrm{N}$-cadherin expression than the primary tumors, thus supporting the hypothesis that the disseminated tumor cells, deriving from primary tumors with marked mesenchymal features, once inside the brain, undergo the reverse process of EMT called mesenchymal-to-epithelial transation.

Gene expression profiles of miRNAs in lung cancer, aimed at identifying molecular markers as predictor of patient survival, identified several miRNAs targeting genes involved in crucial pathways such as the EGFR- and KRasdependent pathways. ${ }^{[65,66]}$

miR-145, a miRNA involved in metastatic spread in several cancer types and discussed above, has been found to be downregulated in the BM compared to primary lung adenocarcinoma samples and its upregulation in lung adenocarcinoma cells suppresses proliferation of tumor cells.

The mechanism by which miR-145 causes these latter effects was hypothesized to be the targeting c-Myc, EGFR and NUDT1; ${ }^{[67]}$ however, in vitro invasion assays did not confirm that upregulation of miR-145 was implied in lung adenocarcinoma cancer cell migration and invasion.
The miR-145 expression levels were not significantly different between primary lung adenocarcinoma samples with and without lymph node involvement ${ }^{[67]}$ and recent studies have found a downregulation of miR-145 expression in lung cancer primary tumors and BM. Silencing of miR145 was found to contribute to BM via downregulation of the fascin homolog 1 (FSCN1) protein, an actin-binding protein involved in cell migration, and upregulation of miR-145 target protein, such as EGFR, OCT-4, MUC-1, $\mathrm{c}-\mathrm{MY},{ }^{[68,69]}$ that are involved in cell proliferation and survival.

miR-328 has been associated with NSCLC BM and mediates NSCLC migration. In patients with BM, the elevated expression of miR-328 in both primary and brain metastatic NSCLC samples suggests that this miRNA may be involved in driving the access of metastatic cells to the brain. In agreement with this finding, in vitro miR-328 overexpression in A549 and H1703 cells was shown to increase cell migration. ${ }^{[70]}$

Another class of RNAs termed long non-coding RNAs (lncRNAs) appear to play a role in lung cancer metastasis spread. lncRNAs are a class of non-protein coding transcripts, longer than 200 nucleotides, associated with the progression of cancer. Some members of the lncRNAs family are involved in metastases formation such as the metastasis-associated lung adenocarcinoma transcript 1 (MALAT1), HOX anti-sense intergenic RNA, and antisense non-coding RNA in the INK4 locus. ${ }^{[71]}$ In lung cancer cells MALAT-1 was found to enhance cell motility by modulating the expression of motility-related genes ${ }^{[72]}$ and to promote lung cancer BM by inducing EMT in both in vitro and in vivo NSCLC models. ${ }^{[72]}$

Another documented mechanism involved in BM formation is represented by integrin receptors activation. Several studies that have investigated $\alpha v \beta 3, \alpha v \beta 5$ and $\alpha v \beta 6$ expression in BM and corresponding primary tumors ${ }^{[73,74]}$ found that $\alpha v \beta 3$ activation strongly promotes metastatic growth in the brain by inducing endothelial cell proliferation and network formation. ${ }^{[75]}$

Interestingly, a recent study performed on formalin fixed paraffin-embedded human primary NSCLC and BM specimen showed that expression of $\alpha v \beta 3, \alpha v \beta 5$ and $\alpha v \beta 6$ integrins is associated with pathological parameters such as enhanced tumor cell proliferation index and increased hypoxia-inducing factor (HIF-1a) expression. Moreover, $\alpha v \beta 3$ and $\alpha v \beta 5$ were mainly expressed on proliferating endothelium of sprouting vessels, in agreement with previous observations that have hypothesized their involvement in neoangiogenesis. ${ }^{[76]}$

Among factors that stimulate vascular proliferation and vessel formation, MMP have been shown to promote endothelial cell migration and induce vascular endothelial growth factor (VEGF) release, leading to development of 
angiogenic vasculature. ${ }^{[77]}$ In agreement with these findings, in lung carcinoma BM a correlation between MMP2 and angiogenesis was also found. ${ }^{[78]}$ In this study tumors expressing MMP2 display a more proliferating vasculature at the tumor-brain interface compared to MMP2-negative tumors, suggesting that MMP2 expression may be a key player in this process by enhancing both invasion and vascularization.

Fibroblast growth factor receptor 1 (FGFR1) signaling has repeatedly been described as a critical permissive factor for distant spread of cancer cells through induction of EMT, interaction with neural cell adhesion molecule neural cell adhesion molecule and N-cadherin or upregulation of osteopontin and matrix metalloproteases. ${ }^{[79]}$ FGFR1 amplifications are common in squamous cell carcinoma and rare in adenocarcinoma of the lung but a recent study found enrichment of FGFR1 amplifications, not related to patients survival, in BM of NSCLC and adenocarcinomas (5-fold more frequent than in primary tumors) suggesting a specific role of FGFR1 in metastasis formation. ${ }^{[79]}$

In order to identify new molecular features associated to BM formation, chromosomal copy number alterations in NSCLC samples was performed; selectively amplified regions of primary lung adenocarcinomas $(5 \mathrm{q} 35,10 \mathrm{q} 23$ and 17q23-24) were identifi ed as signifi cantly associated with the development of early BM within 3 months after first diagnosis of primary tumors. Interestingly, those regions were found to contain putative metastasis promoting genes, such as NeurL1B, ACTA2, FAS and ICAM2,, ${ }^{[0]}$ but the biological significance of these amplifi cations still remains to be elucidated.

\section{BREAST CANCER}

Breast cancer types are routinely classified on the basis of clinical parameters (age, lymph node status, tumor size, histological grade) and pathological markers that usually direct clinicians for the therapy [estrogen receptor (ER), progesterone receptor (PR), human epidermal growth factor receptor 2 (HER2)]. During the last 15 years, 5 sub-types of breast cancer have been identified, on the basis of molecular markers: luminal A, luminal B, HER2-enriched, basal-like and claudin-low. ${ }^{[81]}$

In patients with breast cancer BM are less common than bone or visceral metastases and frequently represent a late event; nevertheless, up to $16 \%$ of metastatic breast cancer patients develop clinically significant BM while autopsy studies showed that up to $30 \%$ of patients actually develop brain disease. ${ }^{[3,82]}$

Several risk factors have been associated with the development of BM in patients with metastatic breast cancer, particularly the young age (35 or younger), HER2enriched sub-type and triple-negative breast cancer (ER ${ }^{-}$,
PR $^{-}$, HER2 $\left.{ }^{-}\right) \cdot{ }^{[83]}$ Patients with HER2-positive metastatic breast tumors are 2-4 times more likely to develop CNS tumors than patients with HER2-negative disease ${ }^{[82]}$ and patients with triple negative breast cancer and basal like breast cancer (BLBC) also appear to be at a high risk for developing BM. ${ }^{\left[{ }^{[8]}\right.}$

The HER2/neu gene is amplified in $20-25 \%$ of primary breast cancer cases; however, gene expression profiles can vary between the primary tumor and metastatic formations and therefore it could not be correct to assume that the HER2 status of the metastatic tumor reflects that of the primary tumor. ${ }^{[85]}$ Biopsies of metastases could provide essential informations in the case of HER2 expression discordance, thus redirecting therapeutic strategies by clinicians. It was found that loss of HER2-positive status in metastatic tumors from patients with primary HER2-positive breast cancer is related to therapeutic treatments with chemotherapy with or without trastuzumab and in addition, patients with HER2 discordance between their primary and metastatic tumors have shorter OS. ${ }^{[85]}$

Another study found that 243 genes were up or downregulated in brain metastatic cell lines, compared to the primary tumor derived cell line ${ }^{[86]}$ and that the expression of 17 genes was correlated with brain relapse. Interestingly, the expression of these 17 genes in breast tumors was not associated with relapse to bones, liver or lymph nodes and the association with brain relapse was significant within ERtumours and in patients who received no adjuvant therapy. A sub-set of these 17 genes that includes prostaglandinsynthesizing enzyme COX2, collagenase-1 (MMP1), angiopoietin-like 4, LTBP1 and FSCN1, the putative metastasis suppressor retinoic acid receptor responder three and heparin-binding EG plays fundamental roles in cell extra-vasation and invasion and in general, in supporting cancer cells migration and survival. ${ }^{[87-91]}$

Among the genes upregulated in breast cancer BM, an important role is also played by the $\alpha 2,6$-sialyltransferase (ST6GALNAC5) because its mRNA levels were found to be notably higher in brain metastatic cells than in parental, primary tumor derived cell lines. ${ }^{[86]}$ Sialyltransferases are a family of at least 18 different intra-cellular Golgi membrane-bound glycosyltransferases that catalyse the addition of sialic acid to gangliosides and glycoproteins. Cell-surface sialylation has been implicated in cell-cell interactions $^{[92]}$ and metastatic cells overexpressing the ST6GALNAC5 messenger, compared to the parental cell lines, showa more marked adhesive behaviour to monolayers of human primary brain endothelial cells. Conversely, ST6GALNAC5-knockdown decreased the brain metastatic activity of BM derived cells. ${ }^{[86]}$

Another gene implicated in BM is hexokinase 2 (HK2). HK2 is one of four members of the HK family that includes HK1, HK2, HK3 and Glucokinase, enzymes involved 
in glycolysis by phosphorylating glucose to produce glucose-6-phosphate. A microarray study, comparing gene expression profiles of BM and primary breast tumors, found an overexpression of $\mathrm{HK} 2$ in BM. ${ }^{[93]} \mathrm{HK} 2$ is overexpressed in several cancer types, compared to normal tissues, and its overexpression is generally related to a poor prognosis; ${ }^{[94]}$ its upregulation in BM suggests that it could be instrumental for cell growth under conditions of limited nutrient availability.

Also, in a recent work 86 matched BM and primary tumors were analyzed by whole-exome sequencing and the authors found that metastatic samples, though showing common features with the primary counterpart, display alterations particularly related to $\mathrm{PI} 3 \mathrm{~K} / \mathrm{AKT} / \mathrm{mTOR}, \mathrm{CDK}$, and HER2/EGFR cascade. ${ }^{[95]}$

Another gene that appears to have a role in the metastatic behaviour of breast cancer is the Forkhead-box transcription factor $\mathrm{C} 1$ (FOXC1), essential for mesoderm tissue development and highly expressed in the basallike (BLBC) and in the triple-negative breast cancer. Overexpression of FOXC1 in BLBC cells and in MCF-7 cell line increases cell proliferation, migration, invasion and anchorage-independent growth of MCF-7 cells in soft agar. ${ }^{[96]}$ The mechanism underlying FOXC1-mediated invasive behaviour is the induction of MMP7 expression in breast cancer cells and interestingly, both FOXC1 and MMP7 are overexpressed in BLBC samples, suggesting a possible new molecular target for BLBC therapy. ${ }^{[97]}$

Finally, an analysis of circulating tumor cells (CTCs) from breast cancer patients demonstrated that CTCs, circulating as single cells or as clusters bound to platelets, express EMT markers such as TGF- $\beta$ and FOXC1, thus supporting the role of EMT in metastasic cells and indicating $\mathrm{FOXC1}$ as a reliable peripheral marker of breast cancer dissemination. ${ }^{[98]}$

\section{MELANOMA}

Malignant melanoma is a frequently lethal malignant tumor that accounts for $4 \%$ of all skin cancers but it is responsible for $80 \%$ of skin-cancer deaths. ${ }^{[99]} \mathrm{BM}$ are a frequent complication in melanoma patients, and unlike in other solid tumors, arise independently from other visceral metastasis. Many melanoma patients are cured after excision of the primary tumor but, in some cases, a disease recurrence appears in different sites as metastatic lesions ${ }^{[100]}$ suggesting that melanoma cells had already spread before excision of the primary tumor.

Melanomas are classified into four major sub-types according to their histological features: lentigo maligna melanoma, superficial spreading melanoma, acral lentiginous melanoma and nodular melanoma. ${ }^{[101]}$ A series of parameters are usually taken into account for patient prognosis: tumor thickness, tumor location, histological sub-type and ulceration. Melanoma classifi cation based on genetic analysis are instrumental for prognosis and targeted therapy; ${ }^{[102]}$ for example, mutations of $B R A F$, particularly the V600E and V600K mutations, have been identified both in benign melanocytic proliferations and in all stages of metastatic melanoma, with the frequency of $36-45 \%$ BRAF mutations in primary melanomas and $42-55 \%$ in metastatic melanomas. The presence of a BRAF mutation in patients with primary melanoma appears to be related to the OS and to a worse prognosis compared to patients who lack the mutation. ${ }^{[103]}$ Nearly $50 \%$ of melanoma BM display V600 BRAF mutation ${ }^{[104]}$ and the analysis of BRAF alterations in melanoma BM is of critical in the selection of patients for targeted therapy with specific inhibitors.

In a very recent and extensive study the Cancer Genome Atlas program performed a systematic characterization of 333 cutaneous melanomas at the DNA, RNA and protein levels with the specifi c goal to create a catalog of somatic alterations with important and potential implications for prognosis and therapy. ${ }^{[105]}$

The first step of metastasis formation, before detachment from the primary tumor, is supposed to be represented by EMT. During this step cancer melanocytes change their adhesion properties and modify their gene expression profiles that results in changes in the amount of integrins and cadherins at protein levels, ${ }^{[106]}$ associated to an increased expression of EMT markers such as SNA1 (Snail and twist), Wnt, Notch, SPARC and Hedgehog. ${ }^{[107]}$ Early-stage melanocytes express $\mathrm{CDH} 5 /$ non-epithelial cadherin ${ }^{[107,108]}$ that leads to the loss of epithelial adhesion properties and to gain of mesenchimal progenitor cells features.

Melanoma metastatic cells are driven to lymph or blood vessels by concentration gradients of cytokines, chemokines, and growth factors. ${ }^{[109]}$ Like in other metastatic tumors, in the bloodstream most cancer cells undergo anoikis but a sub-set acquires some genetic modifications that confer survival advantages such as anoikis resistance. Deregulated activation of the PI3K/Akt pathway, in particular the increased phosphorylation of Akt3, confers resistance to anoikis to melanoma cancer cells and like in other metastatic tumors, loss of phosphatase and tensin homologue contributes to the Akt pathway deregulation related to the tumor malignancy. ${ }^{[110,111]}$

The circulating melanoma cancer cells that have acquired the ability to survive in the circulatory system may also form microaggregates with platelets or leucocytes and travel protected in bloodstream. ${ }^{[15]}$ These microemboli, once finding a niche in very small size capillaries, promote extra-vasation in tissues displaying the appropriate feature such as brain parenchyma.

It has been found that extra-vasation of melanoma circulating cells is prompted by interleukin-8 (IL-8) secretion by melanoma cells and IL- 8 summons neutrophils 
to establish a connection between neutofils and molecular cocrystals through interaction of ICAM-1 protein and $\beta 2$ integrin. ${ }^{[12]}$ Subsequently, the neutrophil-melanoma cell complex binds to endothelial cells of capillaries to promote brain tissue invasion and metastasis growth.

Neoangiogenesis, prompted by VEGF release and increase in levels of HIF-1a, is another necessary step for the tumor growth that regulates tumor cell-microenvironment interactions. ${ }^{[112]}$

Finally, in the brain, astrocytes forming and surrounding the tumoral niche may play a protective role towards the tumor cells growth, including melanoma $\mathrm{BM}$, by priming reactive astrocytosis or protecting tumor cells from cytotoxicity induced by chemotherapeutic drugs. ${ }^{[13]}$

\section{CONCLUSION}

The emerging picture depicted here appears quite complicated and the genes, with the related cellular mechanisms, that have been found to be involved in BM carry out a number of different but still interrelated functions. In addition, a plethora of different cell types like platelets, leukocytes, endothelial cells and astrocytes cooperate all together to sustain the survival of metastatic cells in the blood flow and in the brain parenchyma.

However, although the intrinsic complexity of BM appears to be a daunting task, recent findings may boost the efforts in the field. The development and refinement of existing in vitro three-dimension models of $\mathrm{BBB}$, traditionally employed in the screening of drugs or molecule designed to cross the $\mathrm{BBB}$, could be used as a novel approach to investigate the genotype and phenotype of cancer cells that migrate through artifi cial BBBs. ${ }^{[14,115]}$

Also, the previous mentioned breakthrough discovery of the presence of lymphatic vessels in the brain could open an avenue of cutting edge experimental approaches in the study of CTCs and BM.

\section{Financial support and sponsorship}

Nil.

\section{Conflicts of interest}

There are no conflicts of interest.

\section{REFERENCES}

1. Gavrilovic IT, Posner JB. Brain metastases: epidemiology and pathophysiology. J Neurooncol 2005;75:5-14.

2. Kondziolka D, Shin SM, Brunswick A, Kim I, Silverman JS. The biology of radiosurgery and its clinical applications for brain tumors. Neuro Oncol 2015;17:29-44.

3. Nayak L, Lee EQ, Wen PY. Epidemiology of brain metastases. Curr Oncol Rep 2012;14:48-54.

4. Ba JL, Jandial R, Nesbit A, Badie B, Chen M. Current and emerging treatments for brain metastases. Oncology 2015;29:250-7.

5. Friedl P, Alexander S. Cancer invasion and the microenvironment: plasticity and reciprocity. Cell 2011;147:992-1009.

6. Langley RR, Fidler IJ. The seed and soil hypothesis revisited--the role of tumor-stroma interactions in metastasis to different organs. Int J Cancer 2011;128:2527-35.

7. Saitoh M. Epithelial-mesenchymal transition is regulated at posttranscriptional levels by transforming growth factor- $\beta$ signaling during tumor progression. Cancer Sci 2015;106:481-8.

8. Lindsey S, Langhans SA. Crosstalk of Oncogenic Signaling Pathways during Epithelial Mesenchymal Transition. Front Oncol 2014;4:358.

9. Pasquier J, Abu-Kaoud N, Al Thani H, Rafii A. Epithelial to Mesenchymal Transition in a Clinical Perspective. J Oncol 2015;2015:792182.

10. Mori S, Kodaira M, Ito A, Okazaki M, Kawaguchi N, Hamada Y, Takada Y, Matsuura N. Enhanced expression of integrin $\alpha v \beta 3$ induced by TGF- $\beta$ is equired for the enhancing effect of Fibroblast Growth Factor 1 (FGF1) in TGF- $\beta$-induced Epithelial-Mesenchymal Transition (EMT) in mammary epithelial cells. PLoS One 2015; 10:e0137486.

11. Li W, Zhang B, Li H, Zhao C, Zhong Y, Sun J, Lv S. TGF $\beta 1$ mediates epithelial mesenchymal transition via $\beta 6$ integrin signaling pathway in breast cancer. Cancer Invest 2014;32:409-15.

12. Parvani JG, Galliher-Beckley AJ, Schiemann BJ, Schiemann WP. Targeted inactivation of $\beta 1$ integrin induces $\beta 3$ integrin switching, which drives breast cancer metastasis by TGF- $\beta$. Mol Biol Cell 2013;24:3449-59.

13. Panzeri S, Zanella S, Arosio D, Vahdati L, Dal Corso A, Pignataro L, Paolillo M, Schinelli S, Belvisi L, Gennari C, Piarulli U. Cyclic isoDGR and RGD peptidomimetics containing bifunctional diketopiperazine scaffolds are integrin antagonists. Chemistry 2015;21:6265-71.

14. Hugo H, Ackland ML, Blick T, Lawrence MG, Clements JA, Williams ED, Thompson EW. Epithelial--mesenchymal and mesenchymal-epithelial transitions in carcinoma progression. J Cell Physiol 2007;213:374-83.

15. Labelle M, Begum S, Hynes RO. Direct signaling between platelets and cancer cells induces an epithelial-mesenchymal-like transition and promotes metastasis. Cancer Cell 2011;20:576-90.

16. Tang YN, Ding WQ, Guo XJ, Yuan XW, Wang DM, Song JG. Epigenetic regulation of Smad2 and Smad3 by profilin-2 promotes lung cancer growth and metastasis. Nat Commun 2015; 10;6:8230.

17. Zhang L, Zhang J, Ma Y, Chen J, Dong B, Zhao W, Wang X, Zheng Q, Fang F, Yang Y. Testicular orphan receptor 4 (TR4) is a marker for metastasis and poor prognosis in non-small cell lung cancer that drives the EMT phenotype. Lung Cancer 2015;89:320-8.

18. Kong FF, Qu ZQ, Yuan HH, Wang JY, Zhao M, Guo YH, Shi J, Gong XD, Zhu YL, Liu F, Zhang WY, Jiang B. Overexpression of FOXM1 is associated with EMT and is a predictor of poor prognosis in nonsmall cell lung cancer. Oncol Rep 2014;31:2660-8.

19. Okabe H, Mima K, Saito S, Hayashi H, Imai K, Nitta H, Hashimoto D, Chikamoto A, Ishiko T, Beppu T, Baba H. Epithelial-mesenchymal transition in gastroenterological cancer. J Canc Met Treat 2015;1:183-9.

20. Meng F, Wu G. The rejuvenated scenario of epithelial-mesenchymal transition (EMT) and cancer metastasis. Cancer Metastasis Rev 2012;31:455-67

21. Berezikov E, Guryev V, van de Belt J, Wienholds E, Plasterk RHA, Cuppen E. Phylogenetic shadowing and computational identification of human microRNA genes. Cell 2005;120: 21-4.

22. Garzon R, Fabbri M, Cimmino A, Calin GA, Croce CM. MicroRNA expression and function in cancer. Trends Mol Med 2006;12:580-7.

23. Leung AK. The Whereabouts of microRNA Actions Cytoplasm and Beyond. Trends Cell Biol 2015;25:601-10.

24. Zhang B, Pan X, Cobb GP, Anderson TA. microRNAs as oncogenes and tumor suppressors. Dev Biol 2007;302:1-12.

25. Calin GA, Sevignani C, Dumitru CD, Hyslop T, Noch E, Yendamuri 
S, Shimizu M, Rattan S, Bullrich F, Negrini M, Croce CM. Human microRNA genes are frequently located at fragile sites and genomic regions involved in cancers. Proc Natl Acad Sci USA 2004;101: 2999-3004.

26. Sevignani C, Calin GA, Nnadi SC, Shimizu M, Davuluri RV, Hyslop T, Demant P, Croce CM, Siracusa LD. MicroRNA genes are frequently located near mouse cancer susceptibility loci. Proc Natl Acad Sci USA 2007;104:8017-22.

27. Joyce JA, Pollard JW. Microenvironmental regulation of metastasis. Nat Rev Cancer 2009;9:239-52.

28. Korpal M, Lee ES, Hu G, Kang Y. The miR-200 family inhibits epithelial-mesenchymal transition and cancer cell migration by direct targeting of E-cadherin transcriptional repressors ZEB1 and ZEB2. $J$ Biol Chem 2008;283:14910-4.

29. Zhao C, Xu Y, Zhang Y, Tan W, Xue J, Yang Z, Zhang Y, Lu Y, Hu X. Downregulation of miR-145 contributes to lung adenocarcinoma cell growth to form brain metastases. Oncol Rep 2013;30:2027-34.

30. Sachdeva M, Mo YY. MicroRNA-145 suppresses cell invasion and metastasis by directly targeting mucin 1. Cancer Res 2010;70:378-87.

31. Götte M, Mohr C, Koo CY, Stock C, Vaske AK, Viola M, Ibrahim SA, Peddibhotla S, Teng YH, Low JY, Ebnet K, Kiesel L, Yip GW. miR-145-dependent targeting of junctional adhesion molecule A and modulation of fascin expression are associated with reduced breast cancer cell motility and invasiveness. Oncogene 2010;29:6569-80.

32. Hanniford D, Zhong J, Koetz L, Gaziel-Sovran A, Lackaye DJ, Shang S, Pavlick A, Shapiro R, Berman R, Darvishian F, Shao Y, Osman I, Hernando E. A miRNA-Based Signature Detected in Primary Melanoma Tissue Predicts Development of Brain Metastasis. Clin Cancer Res 2015;21:4903-12.

33. He L, Hannon GJ. MicroRNAs: small RNAs with a big role in gene regulation. Nat Rev Genet 2004;5:522-31.

34. Cortez MA, Bueso-Ramos C, Ferdin J, Lopez-Berestein G, Sood A $\mathrm{K}$, Calin, GA. MicroRNAs in body fluids - the mix of hormones and biomarkers. Nat Rev Clin Oncol 2011;8:467-77.

35. Corrado C, Raimondo S, Chiesi, A, Ciccia F, De LG, Alessandro R. Exosomes as intercellular signaling organelles involved in health and disease: basic science and clinical applications. Int $J \mathrm{Mol} \mathrm{Sci}$ 2013;14:5338-66.

36. Azmi AS, Bao B, Sarkar FH. Exosomes in cancer development, metastasis, and drug resistance: a comprehensive review. Cancer Metastasis Rev 2013;32:623-42.

37. Zhou W, Fong MY, Min Y, Somlo G, Liu L, Palomares MR, Yu Y, Chow A, O'Connor ST, Chin AR, Yen Y, Wang Y, Marcusson EG, Chu P, Wu J, Wu X, Li AX, Li Zi, Gao H, Ren X, Boldin MP, Lin PC, Wang SE. Cancer-secreted miR-105 destroys vascular endothelial barriers to promote metastasis. Cancer Cell 2014;25:501-15.

38. Tominaga N, Kosaka N, Ono M, Katsuda T, Yoshioka Y, Tamura K, Lötvall J, Nakagama H, Ochiya T. Brain metastatic cancer cells release microRNA-181c-containing extracellular vesicles capable of destructing blood-brain barrier. Nat Commun 2015;6:6716.

39. Hoshino A, Costa-Silva B, Shen TL, Rodrigues G, Hashimoto A, Tesic Mark M, Molina H, Kohsaka S, Di Giannatale A, Ceder S, Singh S, Williams C, Soplop N, Uryu K, Pharmer L, King T, Bojmar L, Davies AE, Ararso Y, Zhang T, Zhang H, Hernandez J, Weiss JM, Dumont-Cole VD, Kramer K, Wexler LH, Narendran A, Schwartz GK, Healey JH, Sandstrom P, Jørgen Labori K, Kure EH, Grandgenett PM, Hollingsworth MA, de Sousa M, Kaur S, Jain M, Mallya K, Batra SK, Jarnagin WR, Brady MS, Fodstad O, Muller V, Pantel K, Minn AJ, Bissell MJ, Garcia BA, Kang Y, Rajasekhar VK, Ghajar CM, Matei I, Peinado H, Bromberg J, Lyden D. Tumour exosome integrins determine organotropic metastasis. Nature 2015; doi: 10.1038/nature15756

40. Abbott NJ, Patabendige AA, Dolman DE, Yusof SR, Begley DJ, Structure and function of the blood-brain barrier. Neurobiol Dis 2010;37:13-25
41. Klemke M, Weschenfelder T, Konstandin MH, Samstag Y. High affinity interaction of integrin alpha4beta1 (VLA-4) and vascular cell adhesion molecule 1 (VCAM-1) enhances migration of human melanoma cells across activated endothelial cell layers. $J$ Cell Physiol 2007;212:368-74.

42. Wu K, Fukuda K, Xing F, Zhang Y, Sharma S, Liu Y, Chan MD, Zhou X, Qasem SA, Pochampally R, Mo YY, Watabe K. Roles of the cyclooxygenase 2 matrix metalloproteinase 1 pathway in brain metastasis of breast cancer. J Biol Chem 2015;290:9842-54.

43. Rolland Y, Demeule M, Fenart L, Beliveau R. Inhibition of melanoma brain metastasis by targeting melanotransferrin at the cell surface. Pigment Cell Melanoma Res 2009;22: 86-98.

44. Perides G, Zhuge Y, Lin T, Stins MF, Bronson RT, Wu JK. The fibrinolytic system facilitates tumor cell migration across the bloodbrain barrier in experimental melanoma brain metastasis. $B M C$ Cancer 2006;6: 56.

45. Fazakas C, Wilhelm I, Nagyoszi P, Farkas AE, Haskó J, Molnár J, Bauer H, Bauer HC, Ayaydin F, Dung NT, Siklós L, Krizbai IA.Transmigration of melanoma cells through the blood-brain barrier: role of endothelial tight junctions and melanoma-released serine proteases. PLoS One 2001;6:e20758.

46. Lorger M, Felding-Habermann B. Capturing changes in the brain microenvironment during initial steps of breast cancer brain metastasis. Am J Pathol 2010;176:2958-71.

47. Kienast $Y$, von Baumgarten L, Fuhrmann M, Klinkert WE, Goldbrunner $\mathrm{R}$, Herms J, Winkler F. Real-time imaging reveals the single steps of brain metastasis formation. Nat Med 2010;16:116-22.

48. Blecharz KG, Colla R, Rohde V, Vajkoczy P. Control of the blood-brain barrier function in cancer cell metastasis. Biol Cell 2015;107:342-71.

49. Louveau A, Smirnov I, Keyes TJ, Eccles JD, Rouhani SJ, Peske JD, Derecki NC, Castle D, Mandell JW, Lee KS, Harris TH, Kipnis J. Structural and functional features of central nervous system lymphatic vessels. Nature 2015;523:337-41.

50. Aspelund A, Antila S, Proulx ST, Karlsen TV, Karaman S, Detmar M, Wiig $\mathrm{H}$, Alitalo K. A dural lymphatic vascular system that drains brain interstitial fluid and macromolecules. J Exp Med 2015;212:991-9.

51. Sperduto PW, Kased N, Roberge D, Xu Z, Shanley R, Luo X, Sneed PK, Chao ST, Weil RJ, Suh J, Bhatt A, Jensen AW, Brown PD, Shih HA, Kirkpatrick J, Gaspar LE, Fiveash JB, Chiang V, Knisely JP, Sperduto CM, Lin N, Mehta M. Summary report on the graded prognostic assessment: an accurate and facile diagnosis-specific tool to estimate survival for patients with brain metastases. $J$ Clin Oncol 2012;30:419-25.

52. Oser MG, Niederst MJ, Sequist LV, Engelman JA. Transformation from non-small-cell lung cancer to small-cell lung cancer: molecular drivers and cells of origin. Lancet Oncol 2015;16:165-72.

53. Ramakrishna R, Rostomily R. Seed, soil, and beyond: the basic biology ofbrain metastasis. Surg Neurol Int 2013;4:S256-64.

54. St Hill CA. Interactions between endothelial selectins and cancer cellsregulate metastasis. Front Biosci 2011;16:3233-51.

55. Li B, Zhao WD, Tan ZM, Fang WG. Zhu L, Chen YH. Involvement ofRho/ROCK signalling in small cell lung cancer migration through human brainmicrovascular endothelial cells. FEBS Lett 2006;580:4252-60

56. Liu Y, Liu YS, Wu PF, Li Q, Dai WM, Yuan S, Xu ZH, Liu TT, Miao ZW, Fang WG, Chen YH, Li B. Brain microvascular endothelium induced-annexin A1 secretion contributes to small cell lung cancer brain metastasis. Int J Biochem Cell Biol 2015;66:11-9.

57. Biaoxue R, Xiling J, Shuanying Y, Wei Z, Xiguang C, Jinsui W, Min Z. Upregulation of Hsp90-beta and annexin A1 correlates with poor survival andlymphatic metastasis in lung cancer patients. J Exp Clin Cancer Res 2012;31:70.

58. van Meerbeeck JP1, Fennell DA, De Ruysscher DK. Small-cell lung cancer. Lancet 2011;12:378:1741-55. 
59. Hodkinson PS, Elliott T, Wong WS, Rintoul RC, Mackinnon AC, Haslett C, Sethi T. ECM overrides DNA damage-induced cell cycle arrest and apoptosis in small-cell lung cancer cells through betal integrindependent activation of PI3-kinase. Cell Death Differ 2006;13:1776-88.

60. Ali A1, Goffin JR, Arnold A, Ellis PM. Survival of patients with nonsmall-cell lung cancer after a diagnosis of brain metastases. Curr Oncol 2013;20:300-6.

61. Goldstraw P, Ball D, Jett JR, Le Chevalier T, Lim E, Nicholson AG, Shepherd FA. Non-small-cell lung cancer. Lancet 2011;378:1727-40.

62. Ceresoli GL, Cappuzzo F, Gregorc V, Bartolini S, Crinò L, Villa E. Gefitinib in patients with brain metastases from non-small-cell lung cancer: a prospective trial. Ann Oncol 2004;15:1042-7.

63. Lai CS, Boshoff C, Falzon M, Lee SM. Complete response to erlotinib treatment in brain metastases from recurrent NSCLC. Thorax 2006;61:91.

64. Prudkin L, Liu DD, Ozburn NC, Sun M, Behrens C, Tang X, Moran C, Wistuba II. Epithelial-to-mesenchymal transition in the development and progression of adenocarcinoma and squamous cell carcinoma of the lung. Mod Pathol 2009;22:668-78.

65. Seike M, Goto A, Okano T, Bowman ED, Schetter AJ, Horikawa I, Mathe EA, Jen J, Yang P, Sugimura H, Gemma A, Kudoh S, Croce $\mathrm{CM}$, Harris CC. MiR-21 is an EGFR-regulated anti-apoptotic factor in lung cancer in never-smokers. Proc Natl Acad Sci USA 2009;106:12085-90.

66. Chin LJ, Ratner E, Leng S, Zhai R, Nallur S, Babar I, Muller RU, Straka E, Su L, Burki EA, Crowell RE, Patel R, Kulkarni T, Homer R, Zelterman D, Kidd KK, Zhu Y, Christiani DC, Belinsky SA, Slack FJ, Weidhaas JB. A SNP in a let-7 microRNA complementary site in the KRAS 3' untranslated region increases non-small cell lung cancer risk. Cancer Res 2008;68:8535-40.

67. Zhao C1, Xu Y, Zhang Y, Tan W, Xue J, Yang Z, Zhang Y, Lu Y, Hu X. Downregulation of miR-145 contributes to lung adenocarcinoma cell growth to form brain metastases. Oncol Rep 2013 Nov;30:2027-34.

68. Zhang Y, Lin Q. MicroRNA-145 inhibits migration and invasion by down-regulating FSCN1 in lung cancer. Int $J$ Clin Exp Med 2015;8:8794-802.

69. Donzelli S, Mori F, Bellissimo T, Sacconi A, Casini B, Frixa T, Roscilli G, Aurisicchio L, Facciolo F, Pompili A, Carosi MA, Pescarmona E, Segatto O, Pond G, Muti P, Telera S, Strano S, Yarden Y, Blandino G. Epigenetic silencing of miR-145-5p contributes to brain metastasis. Oncotarget 2015;6:35183-201.

70. Arora S, Ranade AR, Tran NL, Nasser S, Sridhar S, Korn RL, Ross JT, Dhruv H, Foss KM, Sibenaller Z, Ryken T, Gotway MB, Kim S, Weiss GJ.MicroRNA-328 is associated with (non-small) cell lung cancer (NSCLC) brain metastasis and mediates NSCLC migration. Int J Cancer 2011;129:2621-31.

71. Tano K, Akimitsu N. Long noncoding RNAs in cancer progression. Front genet 2012;3:219.

72. Shen L, Chen L, Wang Y, Jiang X, Xia H, Zhuang Z. Long noncoding RNA MALAT1 promotes brain metastasis by inducing epithelialmesenchymal transition in lung cancer. $J$ Neurooncol 2015;121:101-8.

73. Mittelbronn M, Warth A, Meyermann R, Goodman S, Weller M. Expression of integrins alphavbeta3 and alphavbeta5 and their ligands in primary and secondary central nervous system neoplasms. Histol Histopathol 2012;33:405-12.

74. Vogetseder A, Thies S, Ingold B, Roth P, Weller M, Schram $\mathrm{P}$, Goodman SL, Moch H. Alphav-Integrin isoform expression in primary human tumors and brain metastases. Int $J$ Cancer 2013; $133: 2362-71$

75. Lorger M, Krueger JS, O’Neal M, Staflin K, Felding-Habermann B. Activation of tumor cell integrin $\alpha \mathrm{v} \beta 3$ controls angiogenesis and metastatic growth in the brain. Proc Natl Acad Sci USA 2009;106:10666-71.

76. Berghoff AS, Kovanda AK, Melchardt T, Bartsch R, Hainfellner JA, Sipos B, Schittenhelm J, Zielinski CC, Widhalm G, Dieckmann K,
Weller M, Goodman SL, Birner P, Preusser M. $\alpha v \beta 3, \alpha v \beta 5$ and $\alpha v \beta 6$ integrins in brain metastases of lung cancer. Clin Exp Metastasis 2014;31:841-51

77. Deryugina EI, Quigley JP. Tumor angiogenesis: MMP-mediated induction of intravasation- and metastasis-sustaining neovasculature. Matrix Biol 2015;44-46:94-112.

78. Rojiani MV, Alidina J, Esposito N, Rojiani AM. Expression of MMP2 correlates with increased angiogenesis in CNS metastasis of lung carcinoma. Int J Clin Exp Pathol 2010;3:775-81.

79. Preusser M, Berghoff AS, Berger W, Ilhan-Mutlu A, Dinhof C, Widhalm G, Dieckmann K, Wöhrer A, Hackl M, von Deimling A, Streubel B, Birner P. High rate of FGFR1 amplifications in brain metastases of squamous and non-squamous lung cancer. Lung Cancer 2014;8:83-9.

80. Lee HW, Seol HJ, Choi YL, Ju HJ, Joo KM, Ko YH, Lee JI, Nam DH. Genomic copy number alterations associated with the early brain metastasis of non-small cell lung cancer. Int J Oncol 2012;4:2013-20.

81. Prat A, Perou CM. Deconstructing the molecular portraits of breast cancer. Mol Oncol 2011, 5;5-23.

82. Niikura N, Saji S, Tokuda Y, Iwata H. Brain metastases in breast cancer. Jpn J Clin Oncol 2014;44:1133-40.

83. Hung MH, Liu CY, Shiau CY, Hsu CY, Tsai YF, Wang YL, Tai LC, King KL, Chao TC, Chiu JH, Su CH, Lo SS, Tzeng CH, Shyr YM, Tseng LM. Effect of age and biological subtype on the risk and timing of brain metastasis in breast cancer patients. PLoS One 2014;9:e89389.

84. Venkitaraman R, Joseph T, Dhadda A, Chaturvedi A, Upadhyay S. Prognosis of patients with triple-negative breast cancer and brain metastasis. Clin Oncol 2009;21:729-30.

85. Niikura N, Liu J, Hayashi N, Mittendorf EA, Gong Y, Palla SL, Tokuda Y, Gonzalez-Angulo AM, Hortobagyi GN, Ueno NT. Loss of human epidermal growth factor receptor 2 (HER2) expression in metastatic sites of HER2-overexpressing primary breast tumors. $J$ Clin Oncol 2012;30:593-9.

86. Bos PD, Zhang XH, Nadal C, Shu W, Gomis RR, Nguyen DX, Minn AJ, van de Vijver MJ, Gerald WL, Foekens JA, Massagué $\mathrm{J}$. Genes that mediate breast cancer metastasis to the brain. Nature 2009;459:1005-9

87. Gupta GP, Nguyen DX, Chiang AC, Bos PD, Kim JY, Nadal C, Gomis RR, Manova-Todorova K, Massagué J. Mediators of vascular remodelling co-opted for sequential steps in lung metastasis. Nature 2007;446:765-70.

88. Fan C, Oh DS, Wessels L, Weigelt B, Nuyten DS, Nobel AB, van't Veer LJ, Perou CM. Concordance among gene-expression-based predictors for breast cancer. $N$ Engl J Med 2006;355:560-9.

89. Egeblad M, Werb Z. New functions for the matrix metalloproteinases in cancer progression. Nature Rev Cancer 2002;2:161-74.

90. Padua D, Zhang XH, Wang Q, Nadal C, Gerald WL, Gomis RR, Massagué J. TGFbeta primes breast tumors for lung metastasis seeding through angiopoietin-like 4. Cell 2008;133:66-77.

91. Adams JC. Roles of fascin in cell adhesion and motility. Curr Opin Cell Biol 2004:16:590-6.

92. Dall'Olio F, Chiricolo M. Sialyltransferases in cancer. Glycoconj $J$ 2001;18:841-50.

93. Palmieri D, Fitzgerald D, Shreeve SM, Hua E, Bronder JL, Weil RJ, Davis S, Stark AM, Merino MJ, Kurek R, Mehdorn HM, Davis G, Steinberg SM, Meltzer PS, Aldape K, Steeg PS. Analyses of resected human brain metastases of breast cancer reveal the association between up-regulation of hexokinase 2 and poor prognosis. Mol Cancer Res 2009;7:1438-45.

94. Smith TA. Mammalian hexokinases and their abnormal expression in cancer. Br J Biomed Sci 2000;57:170-8.

95. Brastianos PK, Carter SL, Santagata S, Cahill DP, Taylor-Weiner A, Jones RT, Van Allen EM, Lawrence MS, Horowitz PM, Cibulskis K, Ligon KL, Tabernero J, Seoane J, Martinez-Saez E, Curry WT, 
Dunn IF, Paek SH, Park SH, McKenna A, Chevalier A, Rosenberg M, Barker FG 2nd, Gill CM, Van Hummelen P, Thorner AR, Johnson BE, Hoang MP, Choueiri TK, Signoretti S, Sougnez C, Rabin MS, Lin NU, Winer EP, Stemmer-Rachamimov A, Meyerson M, Garraway L, Gabriel S, Lander ES, Beroukhim R, Batchelor TT, Baselga J, Louis DN, Getz G, Hahn WC. Genomic Characterization of Brain Metastases Reveals Branched Evolution and Potential Therapeutic Targets. Cancer Discov 2015;5:1164-77.

96. Ray PS, Wang J, Qu Y, Sim MS, Shamonki J, Bagaria SP, Ye X, Liu B, Elashoff D, Hoon DS, Walter MA, Martens JW, Richardson AL, Giuliano AE, Cui X. FOXC1 is a potential prognostic biomarker with functional significance in basal-like breast cancer. Cancer Res 2010;70:3870-6.

97. Sizemore ST, Keri RA. The forkhead box transcription factor FOXC1 promotes breast cancer invasion by inducing matrix metalloprotease 7 (MMP7) expression. J Biol Chem 2012;287:24631-40.

98. Yu M, Bardia A, Wittner BS, Stott SL, Smas ME, Ting DT, Isakoff SJ, Ciciliano JC, Wells MN, Shah AM, Concannon KF, Donaldson MC, Sequist LV, Brachtel E, Sgroi D, Baselga J, Ramaswamy S, Toner M, Haber DA, Maheswaran S. Circulating breast tumor cells exhibit dynamic changes in epithelial and mesenchymal composition. Science 2013;339:580-4.

99. Miller AJ, Mihm MC, Jr. Melanoma. $N$ Engl J Med 2006;355:51-65.

100. Damsky WE, Theodosakis N, Bosenberg M. Melanoma metastasis: new concepts and evolving paradigms. Oncogene 2014;33:2413-22.

101. The International Agency for Research on Cancer. Pathology and Genetics of Skin Tumours (IARC WHO Classification of Tumours). Lyon: IARC Press; 2006.

102. Fidler IJ. The Biology of brain metastasis: challenges for therapy. Cancer J 2015;21:284-93.

103. Berghoff AS, Preusser M. BRAF alterations in brain tumours: molecular pathology and therapeutic opportunities. Curr Opin Neurol 2014;27:689-96.

104. Muñoz-Couselo E, García JS, Pérez-García JM, Cebrián VO, Castán
JC. Recent advances in the treatment of melanoma with BRAF and MEK inhibitors. Ann Transl Med 2015;3:207.

105. Cancer Genome Atlas Network. Genomic Classification of Cutaneous Melanoma. Cell 2015;161:1681-96.

106. Thompson EW, Newgreen DF, Tarin D. Carcinoma invasion and metastasis: a role for epithelial-mesenchymal transition? Cancer Res 2005;65:5991-5.

107. Caramel J, Papadogeorgakis E, Hill L, Browne GJ, Richard G, Wierinckx A, Saldanha G, Osborne J, Hutchinson P, Tse G, Lachuer $\mathrm{J}$, Puisieux A, Pringle JH, Ansieau S, Tulchinsky E. A switch in the expression of embryonic EMT-inducers drives the development of malignant melanoma. Cancer Cell 2013;24:466-80.

108. Van Roy F. Beyond E-cadherin: roles of other cadherin superfamily members in cancer. Nat Rev Cancer 2014;14:121-34.

109. Wilmott JS, Haydu LE, Menzies AM, Lum T, Hyman J, Thompson JF, Hersey P, Kefford RF, Scolyer RA, Long GV. Dynamics of chemokine, cytokine, and growth factor serum levels in BRAF-mutant melanoma patients during BRAF inhibitor treatment. J Immunol 2014;192:2505-13.

110. Robertson GP. Functional and therapeutic significance of Akt deregulation in malignant melanoma. Cancer Metastasis Rev 2005;24:273-85.

111. Stahl JM, Cheung M, Sharma A, Trivedi NR, Shanmugam S, Robertson GP. Loss of PTEN promotes tumor development in malignant melanoma. Cancer Res 2003;63:2881-90.

112. Mumford BS, Robertson GP. Circulating melanoma cells in the diagnosis and monitoring of melanoma: an appraisal of clinical potential. Mol Diagn Ther 2014;18:175-83.

113. Lin Q, Balasubramanian K, Fan D, Kim SJ, Guo L, Wang H, Bar-Eli M,Aldape KD, Fidler IJ. Reactive astrocytes protect melanoma cells from chemotherapy by sequestering intracellular calcium through gap junction communication channels. Neoplasia 2010;12:748-54.

114. Wilhelm I, Krizbai IA. In vitro models of the blood-brain barrier for the study of drug delivery to the brain. Mol Pharm 2014;11:1949-63.

115. Hopkins AM, DeSimone E, Chwalek K, Kaplan DL. 3D in vitro modeling of the central nervous system. Prog Neurobiol 2015;125:1-25. 